\title{
Pathogenicity Test of Fusariumspp on Gaharu Seedlings (Aquillariamalaccensis)
}

\author{
Nurbaya $^{11}$, Tutik Kuswinanti ${ }^{2}$, Baharuddin ${ }^{2}$, Ade Rosmana ${ }^{2}$ Dan Syamsuddin Millang ${ }^{3}$ \\ ${ }^{1}$ Graduate School Faculty of Agriculture Hasanuddin University \\ ${ }^{2}$ Departement of Plant Pests and Diseases, Faculty of Agriculture \\ ${ }^{3}$ Faculty of Forestry, Hasanuddin University
}

\begin{abstract}
Pathogenicity test of Fusariumspp on gaharu seedlings A malaccensis. is a species of plant that can produce agar wood as non-timber forest products. Developing seedlings is generally not intended to produce timber, but rather to produce agarwood resin formed due to the response of plants on microbial infections, especially fungi. The purpose of this study was to determine the level of virulence of the fungus Fusarium spp.A.malaccensis seeds. There are eleven isolates of the fungus Fusarium are a collection of Nunukan Regency, North Kalimantan, for the seedlings are infected A malaccensis. The results showed that $F$. solani. five isolates originating from Southern Krayan, South Nunukan and isolates both from KrayanInduk, a high level of virulence, because the seeds of $A$ malaccencis dead on the third week and fourth week of observation. While Fsolani isolates originating from the first and second isolates from Southern Krayan, first Fusarium isolates from KrayanInduk, F.oxysporum derived from the three isolates and isolates from Southern Krayan third of Lumbis, a middle level of virulence. Isolates of Fusarium sp. isolates originating from the first Lumbis, F. fujikuroi isolates derived from both isolates and isolates F. ambrosium Lumbis derived from the four isolates South Krayan, showed a low level of virulence.
\end{abstract}

Key Words: Patogenitas, Fusariumspp, Aquillariamalaccensis

\section{INTRODUCTION}

Plants gaharu is one commodity non timber forest products (NTFPs) that have high economic value, even have many benefits such as: the manufacture of perfume, air freshener, incense, cosmetics and traditional medicine (medicine kidney pain, toothache, rheumatism, pain reduction, power adders and bidders can) (Sudrajat, 2003). Agar wood is also used in rituals and religious ceremonies and beliefs devotional objects such as beads and rosaries (Barden et al, 2000).Agar wood is a product in the form of dense clumps of blackish brown or black in color and fragrant wood found on the roots of the plant or tree aloes (Siran, 2010). Most aloes found in agar wood trees are injured, either naturally by biotic factors such as wind, rain or lightning, as well as biotic by microorganisms. A biotic factors are factors that are difficult to imitate because it cannot be the basis of the production process in the industry (Mucharromah, 2010), but it is not systemic abiotic factors that could spread to other parts of the plant timber is still considered healthy (Santoso et al, 2010).

While the formation of agar wood by biotic factors may be caused by microorganisms (Mucharromah, 2010). The mechanism of the formation of agar wood by microorganisms can be spread any other part of the plant as the cause of this mechanism are organisms that do all the activities required for life (Santoso et al, 2010). Formation of agar wood dominated by species of Fusariumspp ranging from 90-100\% (Santoso et al, 2006). However, the biology of fungi and their interaction with the tree aloes as inducers aspect sapwood formation has not been widely studied.

The interaction of the fungus with its host is the most important thing in the test fungi alpathogenicity and strategies in penetrating (Mendgen\&Deising, 1993). Interaction between the host plants pathogenic fungi cause physiological changes in plants that preceded the changes in cells, tissues and organs of plants (Kunoh, 1995). Physiological changes in plants from leaf chloros is, discoloration in the wood can even lead to death of the infected host plants, because of the use of fungi that induce agar wood trees.

${ }^{1}$ Corresponding Author : nurbaya_bima@yahoo.co.id 
Based on the above it is necessary totes the pathogen city of Fusariums pp research on gaharu seedlings(A. malaccensis) to determine Fusariums pp viulen induce agar wood trees inorder to restore the status of commodity scarcity or extinct on into flagship product.

\section{Material AND Methods}

1.Place and Time: Research Fusariumspp pathogenicity testcarried out at the Division of Agricultural Biotechnology Center Biotechnology Research and DevelopmentLaboratory of Integrated LP2M and Hasanuddin University in Makassar. This study was conducted from February2014.

2.Tools Andmaterial:The tools used are: laminar air flow, ovens, petri dish, autoclafand others. While thematerials used are: 11isolates ofthe fungusFusariumsppderivedfromNunukanNorth Borneo, the aloe plant(A. malaccensis).

Virulence Test of Fusariumspp at Agar wood seedlings. Virulence test conducted on plant seeds of A. malaccensis; healthy age \pm six months with a diameter of $0.5 \mathrm{~cm}$, and a height $\pm 30 \mathrm{~cm}$. To determine the effectiveness of isolates of the fungus, the bark of wounded plant seeds along the $\pm 2 \mathrm{~cm}$, with a scalpel that had been sterilized with $70 \%$ alcohol and burning. The entire surface of the rods were wounded affixed with one loop test isolates, covered with sterile cotton that has been moistened with sterile distilled water and wrapped with tape so as not to get wet and contaminated. Used as the stem of the plant that just hurt without being treated as appositive control and a healthy plant as a negative control. Observations were made every week for a month. This study used a completely randomized design(CRD), which consists of 11 isolates of the funguses treatments with three replications so that the required amount of plant seeds plant seeds as much as33plus one control(+) and control(-), so the number of seeds usedas35seed plant.

Observation parameters include: the intensity of isolates of Fusariumspp in the aloe plant seedlings started 1 week after the application isolates and observed for a month. Absolute intensity of the attack is calculated using the formula, $\mathrm{I}=\frac{a}{\mathrm{~b}} \mathrm{x} 100 \%$, and

The observation of changes in color of the wood is also done to the length and width of the zone of discoloration. Added long zone of color change is a long length of wood that have added color change towards the crown (top) or towards the root (bottom) from the inoculated or wounded. Bark peeled in the inoculated or wounded, and the length change of the color is measured. While the width of the color change was observed in transverse section incision inoculated or wounded.

\section{RESUlt AND DisCUSSIONS}

\subsection{Result}

Test virulence of Fusariumsppatagar wood seedlings:

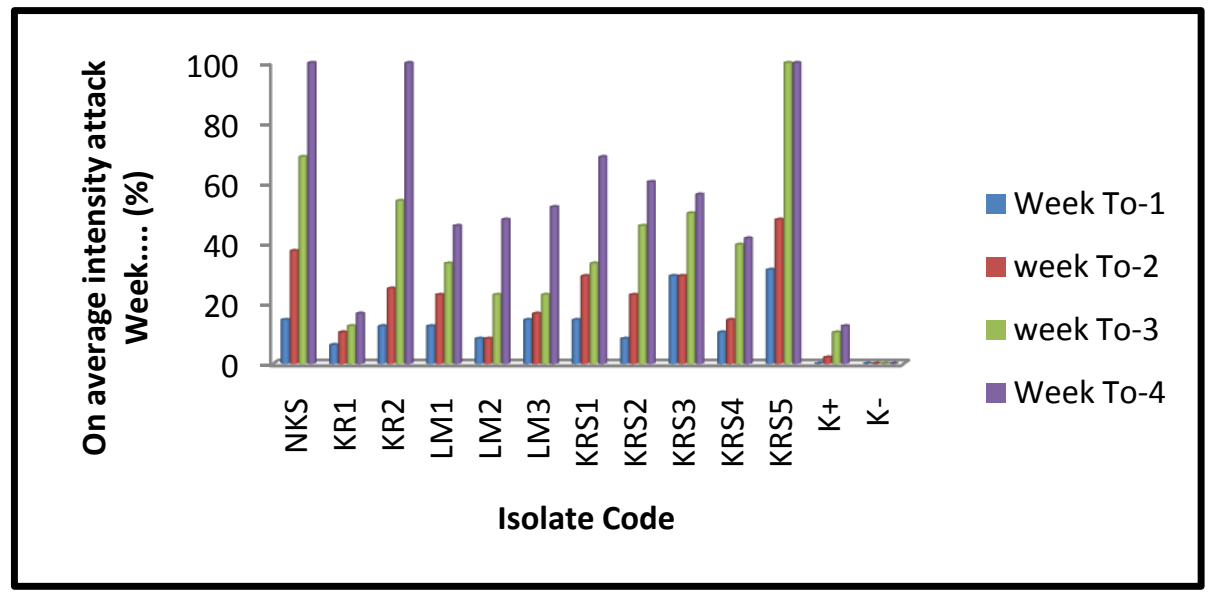

Fig1.Level of Virulence Isolates Fungus Test at Seedsof A.malaccensis

The intensity of the attack of fungi isolates on seedlings of A. malaccensis in the first week to the fourth week, shows that the highest level of virulence caused by isolates KRS 5, death occurs in the third week of plant seeds with the intensity of $100 \%$. Death of plant seeds are also seen in the fourth week of the isolates caused by NKS and 
isolates KR 2, with $100 \%$ intensity of the attacks. The intensity of the lowest attack caused by isolates KR 1 . All the different treatment with the positive control and a negative control (Fig 1).

The intensity of the attack of fungi isolates were observed at the organ level is leaf chloros is and is coloration of wood in the area of inoculation. While the plants were wounded also experienced chlorotic leaves but no change of color of the wood.

Leaf chlorosis initially occurs in the leaves near the inoculation or injured. The leaves of this, there are a fall until the end of observation (Figure 2). On the trunk or injured inoculated with the fungus visible color change from white wood brown to brown-black. While the rod is experiencing wounding without inoculation of the fungus which is a positive control causing a brownish color to white until the end of the observation? In healthy plant seeds as a negative control did not change color until the end of observation (Figure 3)
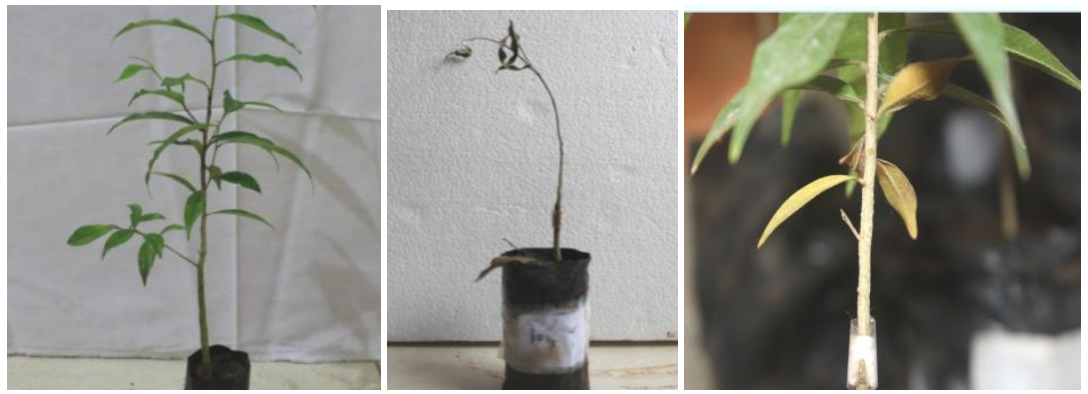

Fig2. Leaf Chlorosis A. malaccensis After inoculation of Fusariumspp(Central), Autumn Leaves(Right) and Healthy Plants(Left)

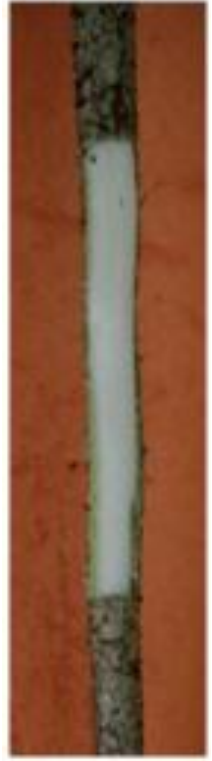

A

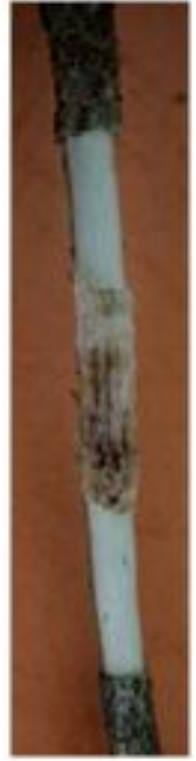

B

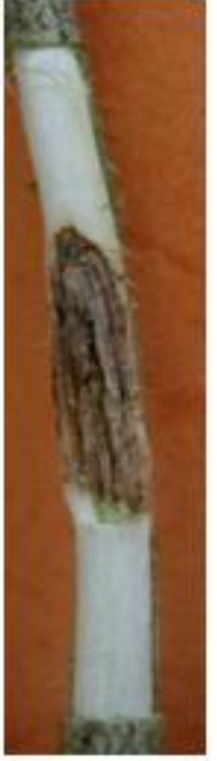

$\mathrm{C}$

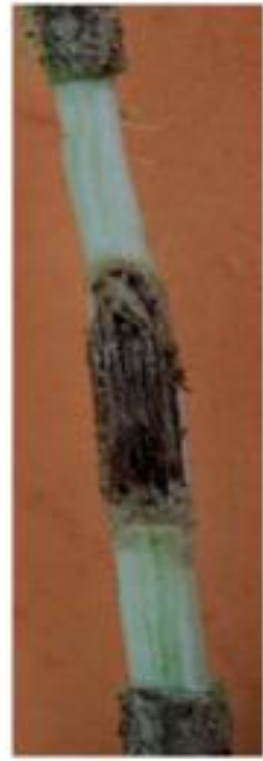

$\mathrm{D}$

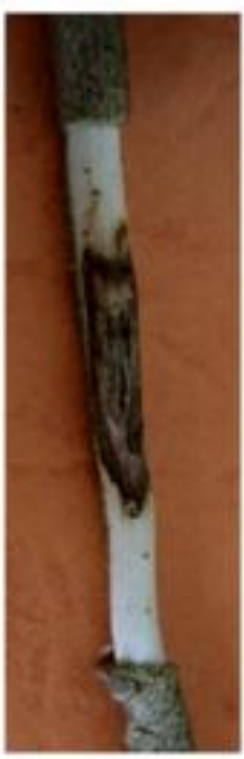

$\mathrm{E}$

Fig3. Changes in Wood Color White, White Brownish, Brown and Brown Black.(A). Control-, (B).Control+, (C) The level of virulence of Light, (D).Mediumlevel ofvirulence, (E).High-Level Virulence

Results of analysis of variance for the intensity of the attack, the ANOVA test on the treatment of the first weekof0.01was significantly different at $5 \%$ level. For the treatment of the second weekof0.00significantly different at 5\% level. Later in the third and fourth weeks of treatment were significantly different for 0.00 at $5 \%$ level. Based on that followed by Duncan test for the intensity of the attacks on the seedlings of A.malaccensisis obtained that, the treatment using 11 isolatesof fungi influential on the level of virulence that occurs in seeds of A.malaccensis. The 
effect of this treatment is very effective to determine the intensity of the attacks which happened in the aloe plant seedlings. IsolatesKRS5, NKSandKR2isolatesmore effectively increase the intensity of the attacks on the aloe plant seeds than other isolates. (Table 1).

Table1.Results of Finger print Analysis Attacks On Seed Variety intensity A.malaccensis

\begin{tabular}{|c|c|c|c|c|}
\hline \multirow[t]{2}{*}{ Isolate } & \multicolumn{4}{|c|}{ The intensity of the attack on the Week----- } \\
\hline & 1 & 2 & 3 & 4 \\
\hline Control - & $0.00^{\mathrm{d}}$ & $0.00^{\mathrm{f}}$ & $0.00^{\mathrm{g}}$ & $0.00^{\mathrm{d}}$ \\
\hline Control + & $0.00^{\mathrm{d}}$ & $1.56^{\mathrm{f}}$ & $3.35^{\mathrm{f}}$ & $3.60^{\mathrm{c}}$ \\
\hline F. solani (NKS) & $3.86^{\mathrm{bc}}$ & $6.15^{\mathrm{ab}}$ & $8.35^{\mathrm{b}}$ & $10.05^{\mathrm{a}}$ \\
\hline KR 1 & $2.69^{\mathrm{c}}$ & $3.35^{\mathrm{e}}$ & $3.67^{\mathrm{f}}$ & $4.15^{\mathrm{c}}$ \\
\hline F. solani(KR 2) & $4.15^{\mathrm{ab}}$ & $5.66^{\mathrm{abc}}$ & $7.35^{\mathrm{bc}}$ & $10.05^{\mathrm{a}}$ \\
\hline F. sp (LM 1) & $3.60^{\mathrm{c}}$ & $4.88^{\mathrm{bcd}}$ & $5.78^{\text {cde }}$ & $6.84^{\mathrm{b}}$ \\
\hline F. fujikuroi(LM 2) & $3.02^{\mathrm{c}}$ & $3.02^{\mathrm{e}}$ & $4.41^{\mathrm{ef}}$ & $7.35^{\mathrm{b}}$ \\
\hline F. oxysporum(LM 3) & $3.86^{\mathrm{bc}}$ & $4.19^{\text {cde }}$ & $4.88^{\text {def }}$ & $7.28^{\mathrm{b}}$ \\
\hline F. solani $(\mathrm{KRS} 1)$ & $3.82^{\mathrm{bc}}$ & $6.00^{\mathrm{ab}}$ & $6.68^{\mathrm{c}}$ & $8.31^{\mathrm{ab}}$ \\
\hline F. solani(KRS 2) & $3.67^{\mathrm{bc}}$ & $4.67^{\mathrm{bcd}}$ & $6.82^{\mathrm{bc}}$ & $7.79^{\mathrm{b}}$ \\
\hline F. oxysporum (KRS 3) & $5.20^{\mathrm{ab}}$ & $5.47^{\mathrm{abc}}$ & $7.06^{\mathrm{bc}}$ & $7.41^{\mathrm{b}}$ \\
\hline F. ambrosium(KRS 4) & $3.28^{\mathrm{c}}$ & $3.82^{\mathrm{de}}$ & $6.21^{\mathrm{cd}}$ & $6.33^{\mathrm{b}}$ \\
\hline F. solani (KRS 5) & $5.66^{\mathrm{a}}$ & $6.97^{\mathrm{a}}$ & $10.05^{\mathrm{a}}$ & $10.05^{\mathrm{a}}$ \\
\hline
\end{tabular}

Description: The numbers followed by different letters in the same column indicate significant differences by Duncan testat $5 \%$ level

Areas of discoloration of wood that form the stems of seedlings of A.malaccens is after among than wounding inoculate dislocates showed varying width and length. Average width of the wood of the highest areas of change found inisolatesKRS5 $1.13 \mathrm{~cm}$ and2.70 $\mathrm{cmin}$ length(Figure 4).

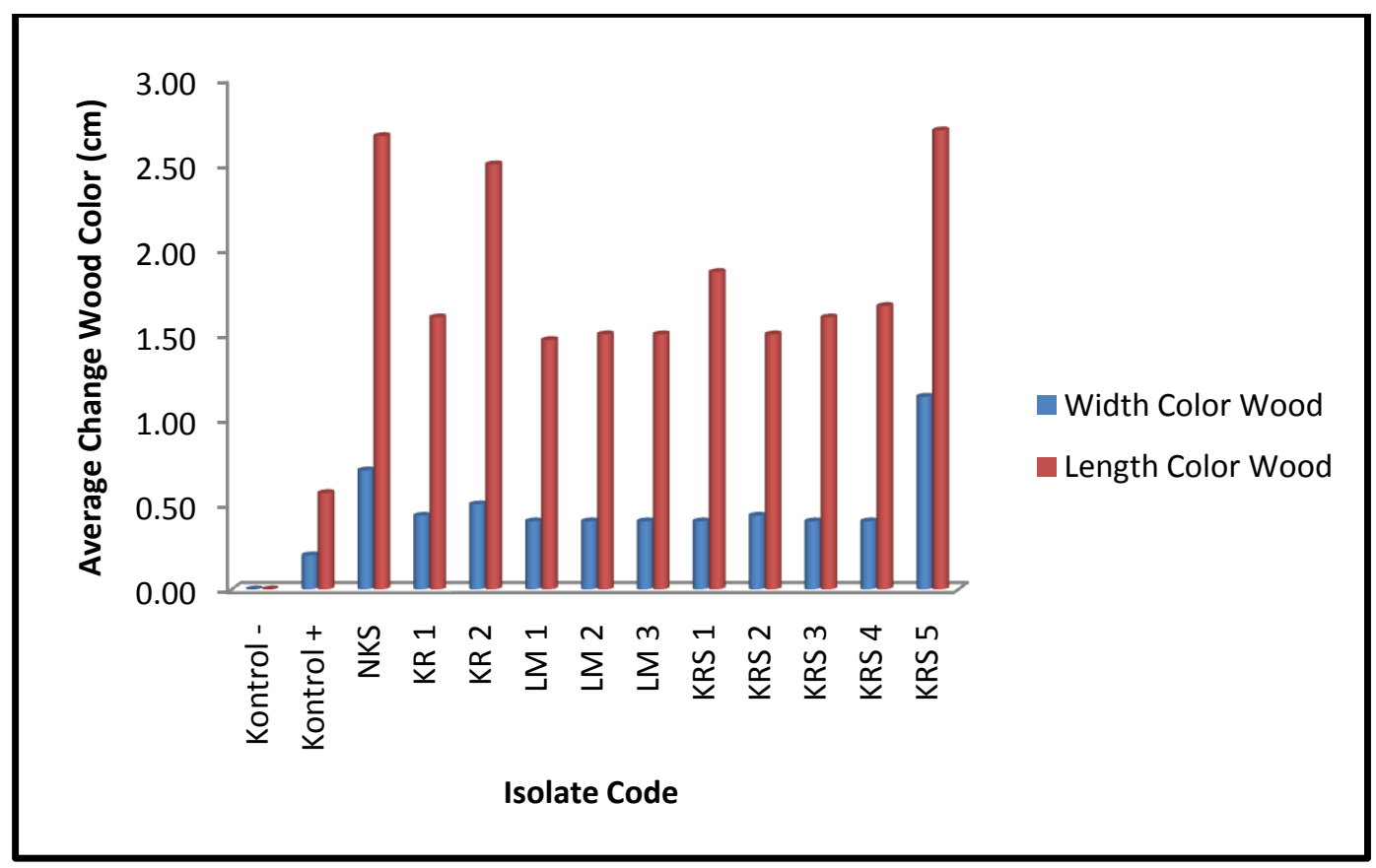

Fig4.ZoneColour Change Seed Timber Trunk A.malaccensis

Results of analysis of variance to change the color of the wood, the ANOVA test on the treatment for a month at 0.00 significantly different at $5 \%$ level. Inoculation of isolates and wounding give significant influence to increase the width and length of the zone change in color of the wood. Based on these results further tested by Duncan test, showed that treatment with 11 isolates affect the formation of areas of change the width and color of the wood on the long stems of seedlings of A. malaccensis. Effect of change in color of the wood is determined by the isolates 
used. KRS5isolatescanform an area ofdiscoloration of wood widest isolates differ from each other and can form an area ofdiscoloration of wood long but not different isolates of NKS(Table 2).

Table2 .Area Wood Colour Change In Trunk Seed A .malaccensis

\begin{tabular}{|c|c|c|}
\hline \multirow{2}{*}{ Isolate } & \multicolumn{2}{|c|}{ Area of Discoloration of Wood $(\mathrm{cm})$} \\
\hline & Width & Lengthy \\
\hline Control - & $1.00^{\mathrm{g}}$ & $0.00^{\mathrm{i}}$ \\
\hline Control + & $1.10^{\mathrm{f}}$ & $1.25^{\mathrm{h}}$ \\
\hline F. solani $(\mathrm{NKS})$ & $1.27^{\mathrm{b}}$ & $1.92^{\mathrm{ab}}$ \\
\hline KR 1 & $1.15^{\mathrm{e}}$ & $1.54^{\mathrm{g}}$ \\
\hline F.solani(KR 2) & $1.23^{\mathrm{c}}$ & $1.88^{\mathrm{b}}$ \\
\hline F. sp (LM 1) & $1.17^{\mathrm{de}}$ & $1.58^{\mathrm{f}}$ \\
\hline F. fujikuroi(LM 2) & $1.17^{\text {de }}$ & $1.59^{\mathrm{df}}$ \\
\hline F. oxysporum(LM 3) & $1.19^{\text {cde }}$ & $1.60^{\mathrm{df}}$ \\
\hline F. solani $($ KRS 1$)$ & $1.21^{\mathrm{cd}}$ & $1.70^{\mathrm{c}}$ \\
\hline F. solani(KRS 2) & $1.19^{\text {cde }}$ & $1.58 \mathrm{f}$ \\
\hline F. oxysporum(KRS 3) & $1.18^{\mathrm{de}}$ & $1.61^{\mathrm{df}}$ \\
\hline F. ambrosium(KRS 4) & $1.19^{\text {cde }}$ & $1.63^{\mathrm{d}}$ \\
\hline F. solani(KRS 5) & $1.46^{\mathrm{a}}$ & $1.95^{\mathrm{a}}$ \\
\hline
\end{tabular}

Description: The numbers followed by different letters in the same column indicate significant differences by Duncan test at $5 \%$ level

\subsection{Discussion}

The results of the study (Figure 1), indicating that the highest intensity of attacks on seedlings of A. malaccensis, occurs in the third week, due to the inoculation of the fungus isolates and wounding. This leads to leaf chlorosis and changes in wood color zones. Death of plant seeds started in the third week by F. solani., 5 isolates from South Krayan (KRS 5), which is then followed by the death of seedlings inoculated with $F$. solani., Isolates from South Nunukan (NKS) and F. solani., 2 isolates from South Krayan (KR 2) in the fourth week. While the seeds of other plants inoculated with fungi isolates were injured and not see death until the end of the observation.

Inoculation of isolates of the fungus on the plant causes physiological changes in plants with disruption of the process of photosynthesis, translocation of water and nutrients, as well as respiration in plants (Figure 2). This leads to changes in plant responses at the level of the organ due to disruption of the availability of nutrients due to wounding. Leaf chlorosis suffered from lack of chlorophyll pigments due to lack of nutrients (Niemann\&Visintini, 2005).

Statistical analysis showed (Table 1), that the intensity of attacks was significantly different at $5 \%$ confidence level, in all samples fungal isolates were used, ranging from observations in the first week until the end of treatment (week four). The highest intensity of attacks that caused $100 \%$ mortality of seeds of plants, found in the seeds of plants inoculated with $F$. solani., Isolates of the fungus KRS 5, NKS, and KR 2, it indicates that the three isolates of this fungus has a high level of virulence of seed plant A. malaccensis. Intensity of $51 \%-70 \%$ found in A. malaccensis seedlings inoculated with $F$. solani isolates., Isolate one of South Krayan (KRS 1), F. oxysporum., 3 isolates from South Krayan (KRS 3), F. solani ., 2 isolates from South Krayan (KRS 2) and F. oxysporum., 3 isolates from Lumbis (LM 3), it indicates that the four isolates have moderate levels of virulence. While the intensity of $15 \%$ $50 \%$ found in A. malaccensis seedlings inoculated with $F$. fujikuroi., 2 isolates of Lumbis (LM 2), $F$. sp., Isolate one of Lumbis (LM 1), F. ambrosia., 4 isolates from South Krayan (KRS 4) and isolates one from Krayan Parent (KR 1), have the low level of virulence.

The level of intensity of the attacks were observed on the leaves of seedling plants, effect on the accumulation of torpedoed compounds in wood tissues, causing discoloration of the stem wood seedlings (Figure 3). To limit the spread of infection due to isolates of the fungus, plant seedlings were inoculated with fungal isolates an area extending beyond the area of infection changes color as the plant hypersensitive response. Hypersensitivity responses of plants can be either cell necrosis or the accumulation of defense compounds (Prins, 2000). 
Isolates of fungi which attack the high intensity, resulting in a color change of area high wood, with a wide range of color change $0.50 \mathrm{~cm}-1.13 \mathrm{~cm}$ and length $2.50 \mathrm{~cm}-2.70 \mathrm{~cm}$. While the intensity of the attack of fungi isolates moderate, and low intensity attacks produce areas of discoloration of wood, with a wide range of color change 0.40$\mathrm{cm} 0.43 \mathrm{~cm}$ and length $1.46 \mathrm{~cm}-1.66 \mathrm{~cm}$. From the results of statistical tests (Table 2), indicating that the width and length to increase the intensity of the color of wood differs significantly higher with increasing width and length of the wood color on medium and low intensity attacks. But for moderate and low intensity attacks are not were not significantly different in the width of the resulting wood color but significantly different on the length of the resulting color of the wood. Wan changes in wood due to fungal infection of plant seeds were significantly different compared to wounding. So that the length and color of the wood is darker an indicator that the aloe plant will produce agar wood compounds. According toBardenetal2000producedthe darker the color the higher the level of pig aloes which will be formed.

\section{CONCLUSION AND SUGGESTIONS}

Isolate with high-level of virulence of fungi are found inisolatesKRS5, NKS, andKR2, which are from species of $F$. solani., show the level of intensity of $100 \%$ in the third week until the end of the observation

\section{REFERENCES}

[1] Barden, A. Noorainie, Awang, Anak.T. Mulliken, and M. Song. 2000. Heart of the matter: Agarwood use and trade and CITES implementation for Aquilariamalaccensis. TRAFFIC International.

[2] Kunoh, H. 1995. Cytologycal Approaches In Understanding Host-Parasite Interaction. Di Dalam Mills D et al, Editor. Moleculer Aspect Of Pathogenecity And Resistance : Requirement For Signal Tranduction. United States Of America: APS Press. Hlm 15-26

[3] Mendgen, K, H Deising. 1993. Infection structures of fungal plant pathogen-a cytological and physiological evaluation. New Phytol124: 193-213.

[4] Mucharromah.2010. Development of Agar wood in Sumatera. Pener bit Research and Development Centerfor Forest and Nature Conservation., Bogor

[5] Nieamann, KO. Visintini. 2005. Assessment of Potential For Remote Sensing Detection Of Bark Beetle-Infested Areas During Green Attack: A Literature Review. Canada: Mountain Pine Beetle Initiative

[6] Santoso, E.1996.Formation of agar woodby means of inoculation .Discussion paper the results of research in supporting sustainable use of forests. Bogor: Center for Forest and Nature Conservation Research and Development, 11 to 12 March1996,pp1-3.

[7] Santoso, E. Pure Kartono. Maman Turjaman. 2010. Induction Technology Producing Agar wood tree. Publisher Center for Research and Development of Forest and Nature Conservation. Bogor 